UCRL-ID-129922

\title{
Installation of Microbes into the Drift Scale Test
}

\section{A. Meike, M. Spragge, B. Pitonzo, C.-I. Chen, L. Hersman, P. Amy, Y.-J. Chuu}

February 27, 1998

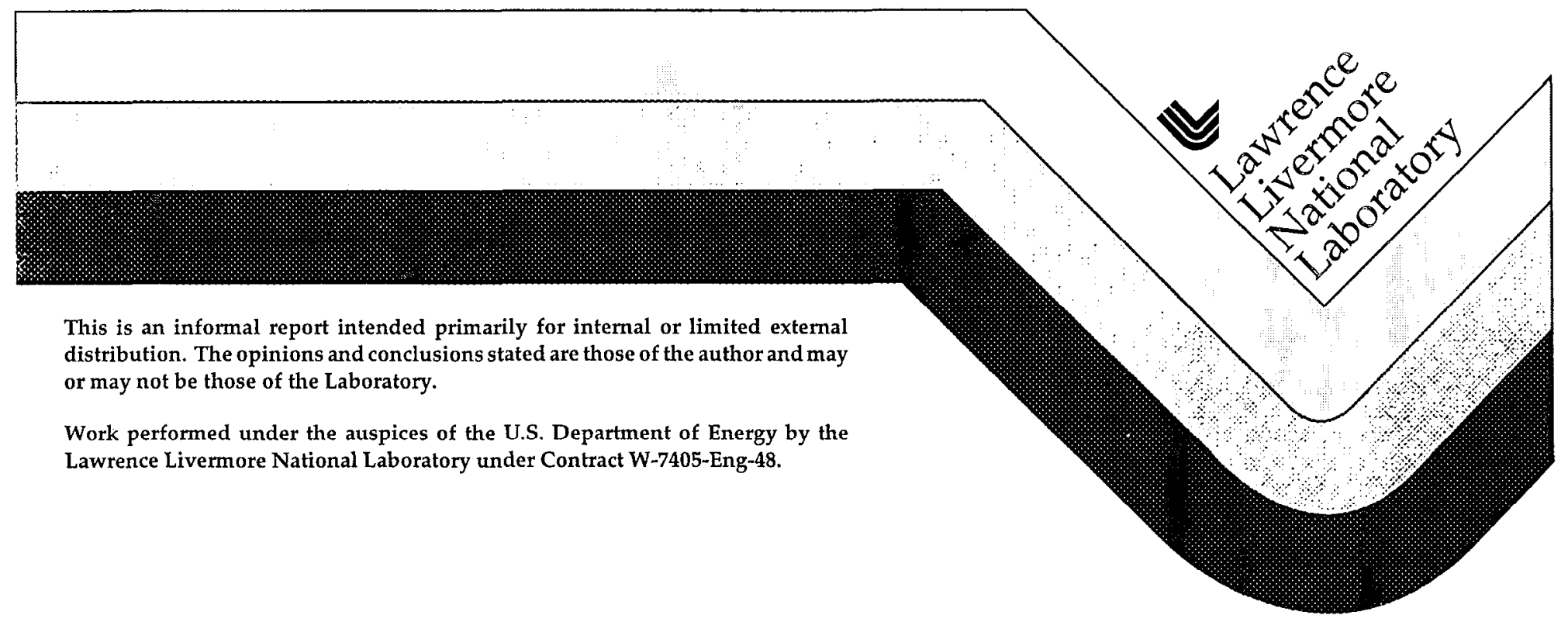




\section{DISCLAIMER}

This document was prepared as an account of work sponsored by an agency of the United States Government. Neither the United States Government nor the University of California nor any of their employees, makes any warranty, express or implied, or assumes any legal liability or responsibility for the accuracy, completeness, or usefulness of any information, apparatus, product, or process disclosed, or represents that its use would not infringe privately owned rights. Reference herein to any specific commercial product, process, or service by trade name, trademark, manufacturer, or otherwise, does not necessarily constitute or imply its endorsement, recommendation, or favoring by the United States Government or the University of California. The views and opinions of authors expressed herein do not necessarily state or reflect those of the United States Government or the University of California, and shall not be used for advertising or product endorsement purposes.

This report has been reproduced directly from the best available copy.

Available to DOE and DOE contractors from the Office of Scientific and Technical Information

P.O. Box 62, Oak Ridge, TN 37831

Prices available from (615) 576-8401, FTS 626-8401

Available to the public from the

National Technical Information Service

U.S. Department of Commerce

5285 Port Royal Rd.,

Springfield, VA 22161 


\title{
Installation of Microbes into the Drift Scale Test
}

\author{
A. Meike ${ }^{1}$, M. Spragge ${ }^{1}$, B. Pitonzo ${ }^{2}$, C.-I. Chen ${ }^{1}$, \\ L. Hersman ${ }^{3}$, P. Amy ${ }^{4}$, and Y.-J. Chuu ${ }^{1}$
}

${ }^{1}$ Lawrence Livermore National Laboratory

${ }^{2}$ Community College of Southern Nevada

${ }^{3}$ Los Alamos National Laboratory

${ }^{4}$ University of Nevada at Las Vegas 


\section{Introduction.}

In the past, the potential significance of the microbial activity on the chemical evolution of a radioactive waste repository, waste package lifetime, and radionuclide transport has been discussed (see e.g. Horn and Meike, 1995). At present those impacts are not understood well enough to determine their significance. The purpose of including the microbial experiments in the Drift Scale Test (Fig. 1) has been to obtain complex process level information about survival and migration of microbes in an environment analogous to a radioactive waste repository. An added advantage is the ability to put our results in the context of the other data (hydrological, mechanical and chemical) that are being obtained in this test. With the goal of understanding the significance of microbial survival and migration in this geological repository environment, we have designed the following tests.

1) Survival/migration test: borehole emplacement of labeled microbes.

2) Survival/migration test: Heated Drift emplacement of labeled microbes.

3) Survival/material-microbe-rock interaction test: carbon steel-microbe-rock and carbon steel-microbe-concrete

4) Sterile collection and freezing of pre-test rock sample.

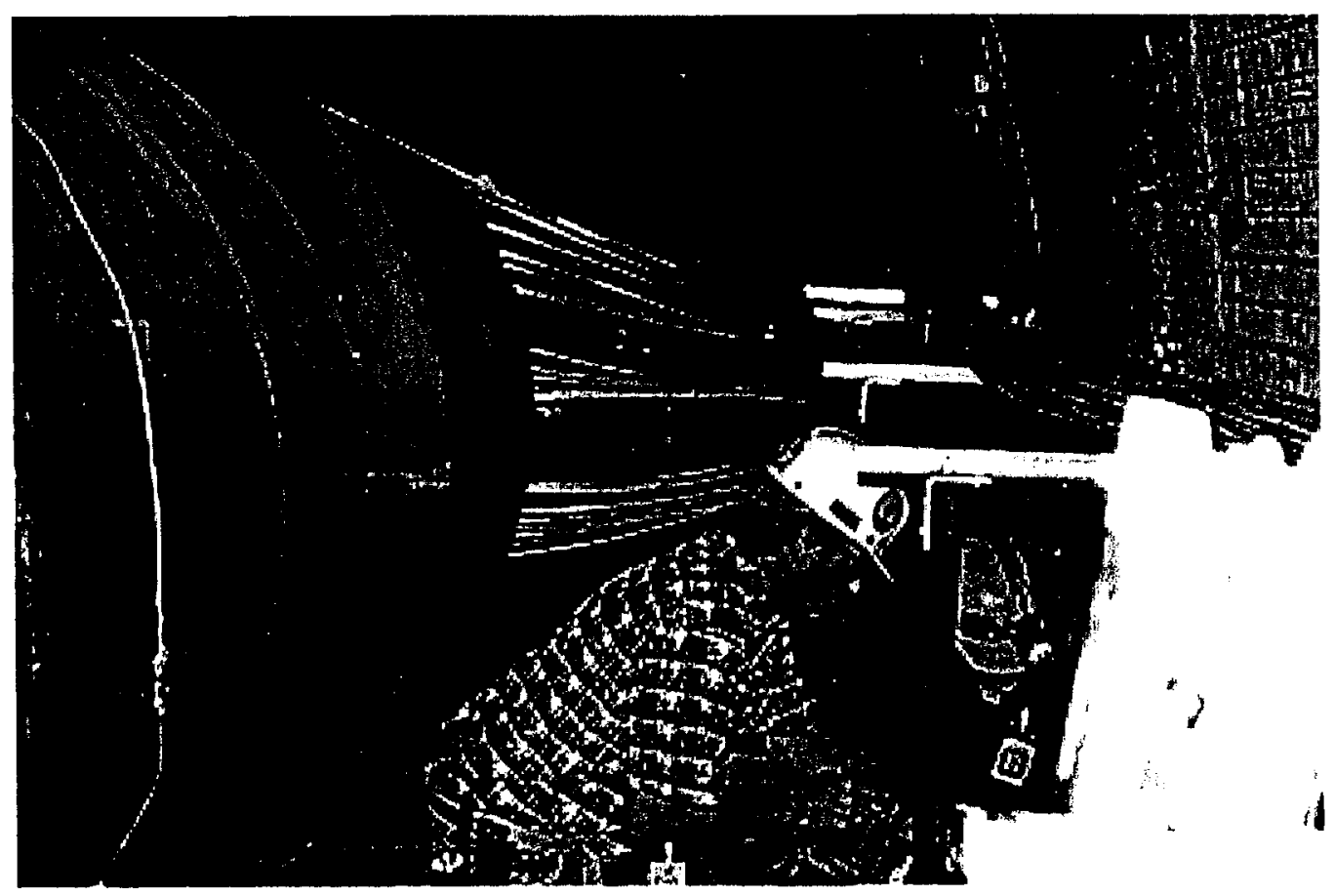

Fig. 1. Heated Drift. View from the end wall toward bulkhead indicates the size of the heater containers.

All tests have been conducted with microbes that are indistinguishable from the microbes that are present in the rock surrounding the Drift Scale Test with the exception of 
a label that will be used to track their progress. These labels do not alter the microbes in a way that affects their function and are thus no more of a concern than the indigenous microbes. The microbes are not pathogenic and have been collected and isolated for the Yucca Mountain Project at during the excavation of the Exploratory Studies Facility (ESF) by Hersman, Amy, and Pitonzo and by Meike and Horn (Fig. 2 a and b).

a.
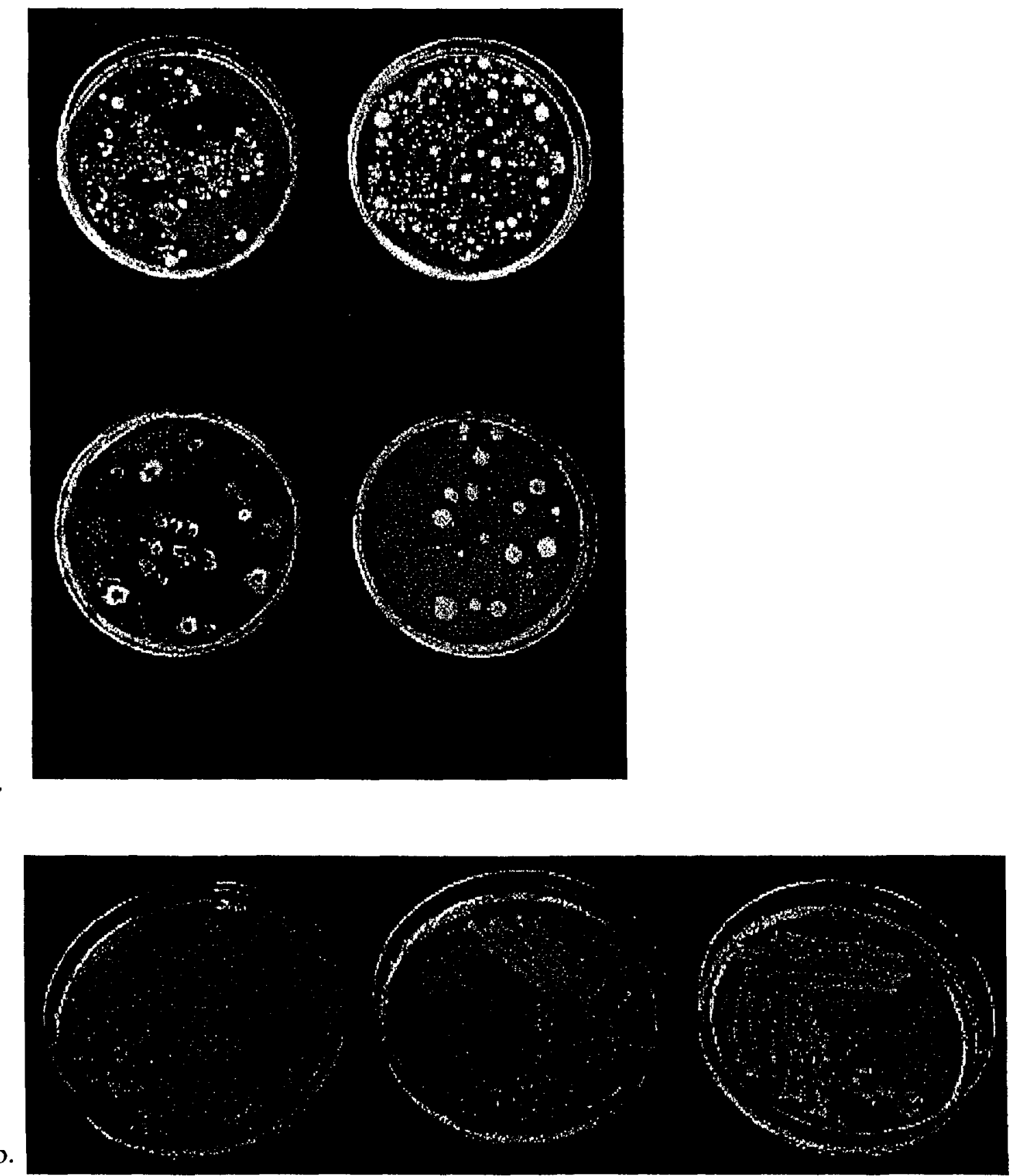

Fig. 2. Bacteria isolated from Exploratory Studies Facility and Large Block Test. a. Cultured crushed rock and rock wash. b. Slime producing isolates. 
The total number of microbes that have been installed in the Drift Scale test for this purpose is far less than the number microbes that have been unintentionally introduced during the construction of the test. The locations of installation points in the Heated Drift are designated in Figure 3. For borehole locations refer also to the schematic illustration of the borehole arrangement for the Drift Scale Test (Weaver, 1996).

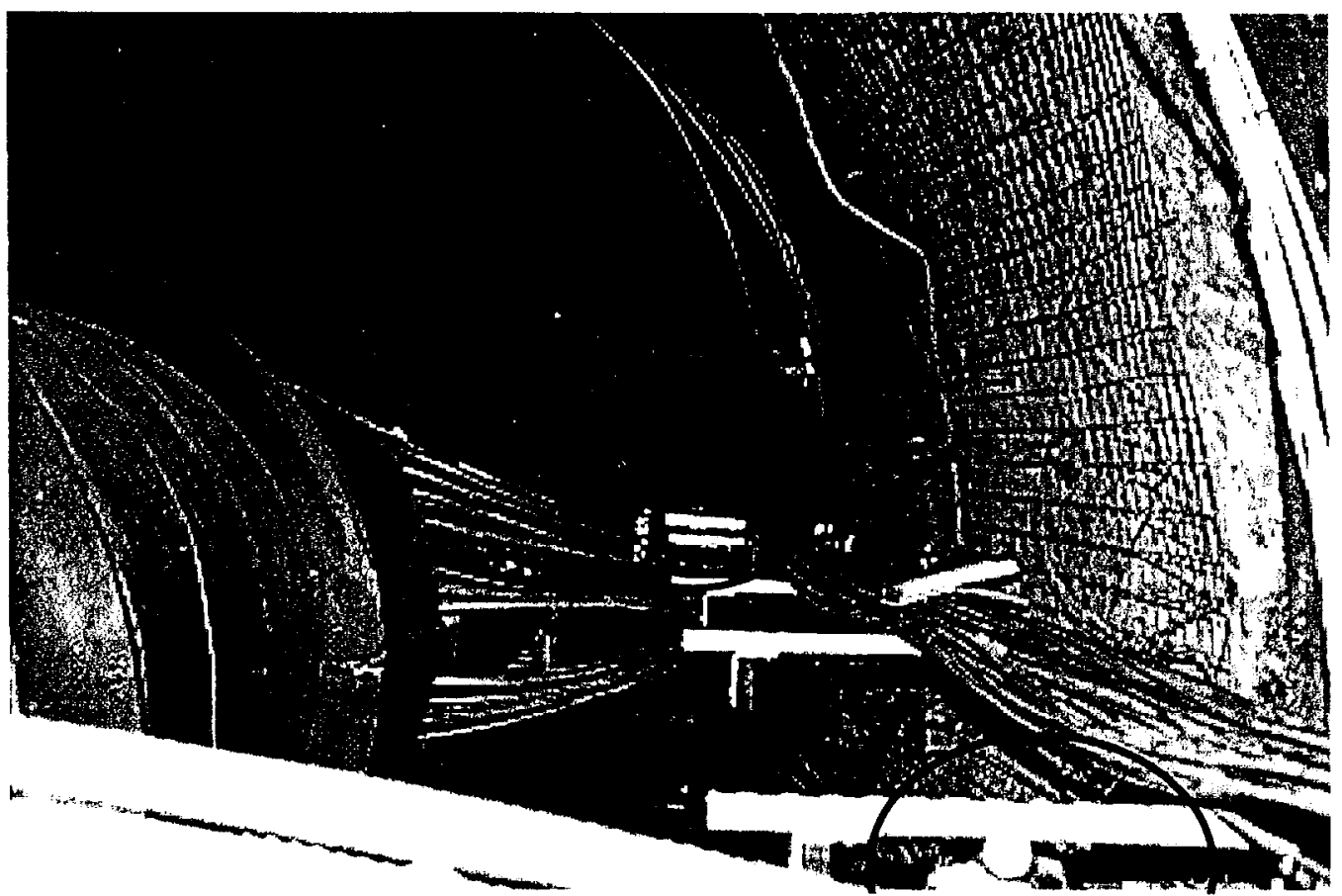

Fig. 3. Heated Drift view toward bulkhead, showing the video camera track (arrow), coupon installation site (foreground circle). Migration/survival microbe installation site (background circle).

\section{Survival/ Migration Tests.}

Two survival/migration tests were installed in the Drift Scale Test. Our goal is to use the opportunity provided by this large scale test to attempt to observe migration of microbes and there long term survival in this perturbed geological environment. Microspherules of the same size and charge as the active microbes were installed with the microbes in order to evaluate the movement of non-living particles in the event that the microbes do not survive, or cannot be traced. The microbes in these tests were necessarily given a label, or marker in order to distinguish them from identical microbes that are existing in the rock. Two distinct sets of microbes and microspherules were installed in two different locations. Microbes were installed in the borehole liners to allow us to determine survival of one species during the test. Microbes were also installed at the wall of the Heated Drift. These microbes were 
installed in proximity to two chemical boreholes to allow some chance of observing migrating microbes or microspherules during the experiment.

\section{A. Borehole emplacement.}

Inflatable Seamist ${ }^{\mathrm{TM}}$ liners are being used to remotely emplace and retrieve a range of devices for the detection of gas and water chemistry in selected boreholes between the Observation drift and the Heated Drift. The liners for boreholes \#71 and \#72, which have been fitted with sorbant pads, spaced $15 \mathrm{ft}$. apart, to retrieve water samples, were selected for the emplacement of microbes. In order to emplace the microbes, the Seamist ${ }^{\mathrm{TM}}$ liners were inflated onto clean sheets of plastic along the observation drift floor. (Fig. 4).

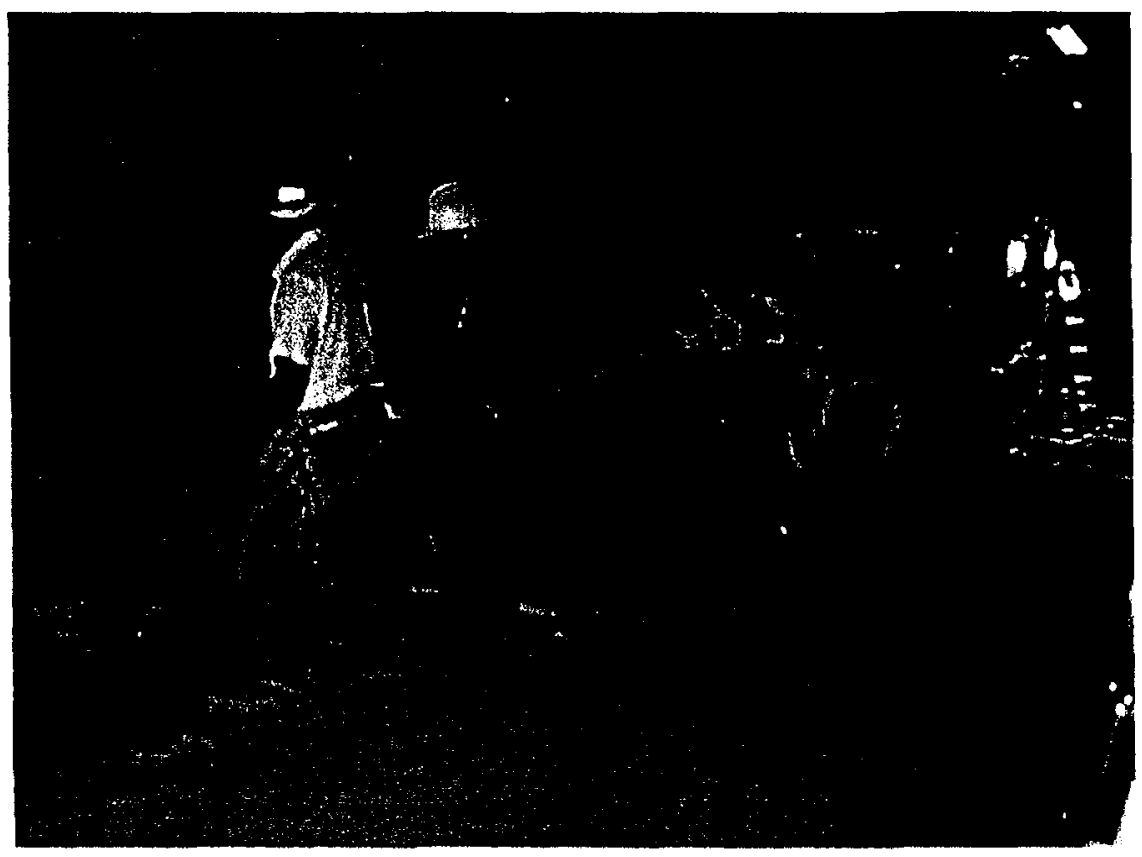

Fig. 4. Inflation of the Seamist ${ }^{\mathrm{TM}}$ borehole liner in the observation drift.

Medium inoculated with labeled pseudomonas (OD at $660 \mathrm{~nm}=0.240, \mathrm{pH}=3.66$ ) and yellow microspherules $\left(1.15 \times 10^{9}\right.$ beads $/ \mathrm{ml}, 1 \mu \mathrm{m} \mathrm{dia}$.), was applied to the each of the chemical pads (Fig. 5). After inoculation, the pad was immediately inverted to the inside of the liner. Each of the ten pads of borehole \#72 liner received $35 \mathrm{ml}$ of inoculated medium and microspherules. $10 \mathrm{ml}$ of inoculated medium was applied to each of the ten pads of borehole \#71 liner. The inoculated medium was applied to the left hand side of the seam of each pad (viewed toward the Heated Drift end of the liner (bottom of the hole)) (Fig. 6). 


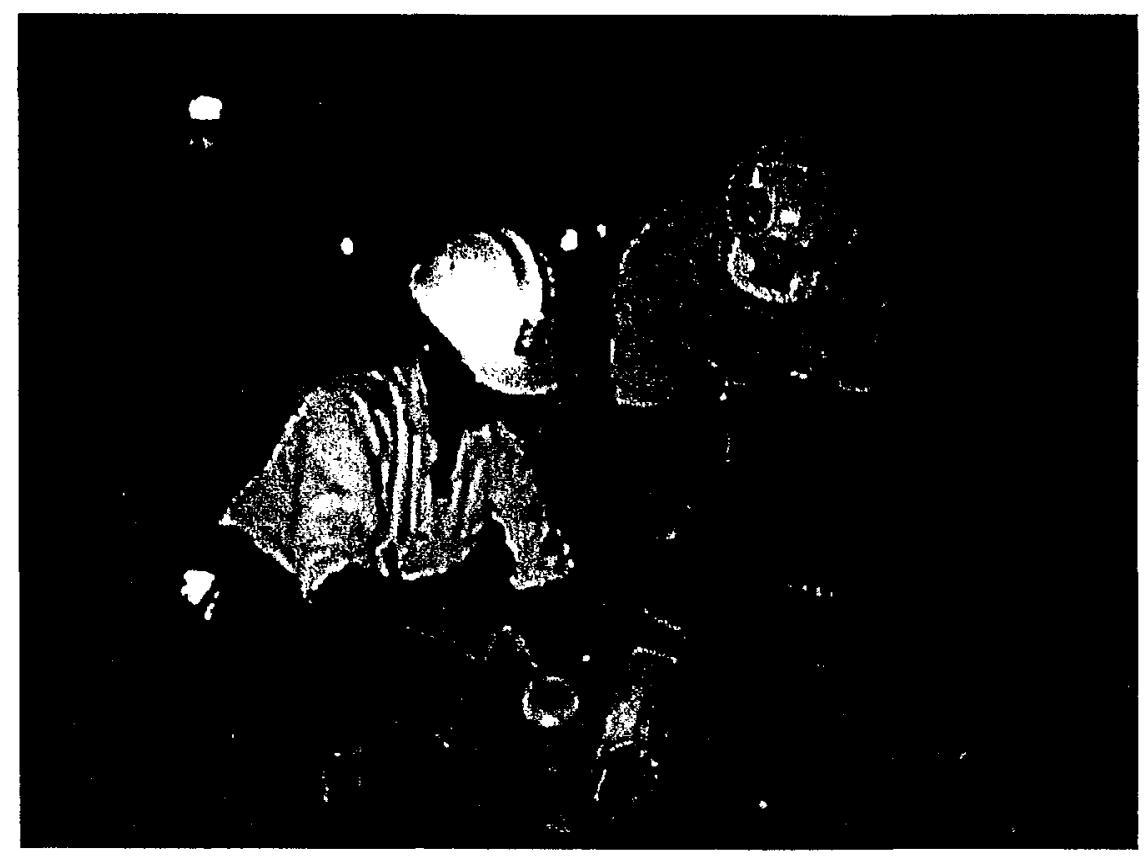

Fig. 5. Each of the ten pads of borehole \#72 liner received $35 \mathrm{ml}$ of inoculated medium and microspherules. $10 \mathrm{ml}$ of inoculated medium was applied to each of the ten pads of borehole \#71 liner.

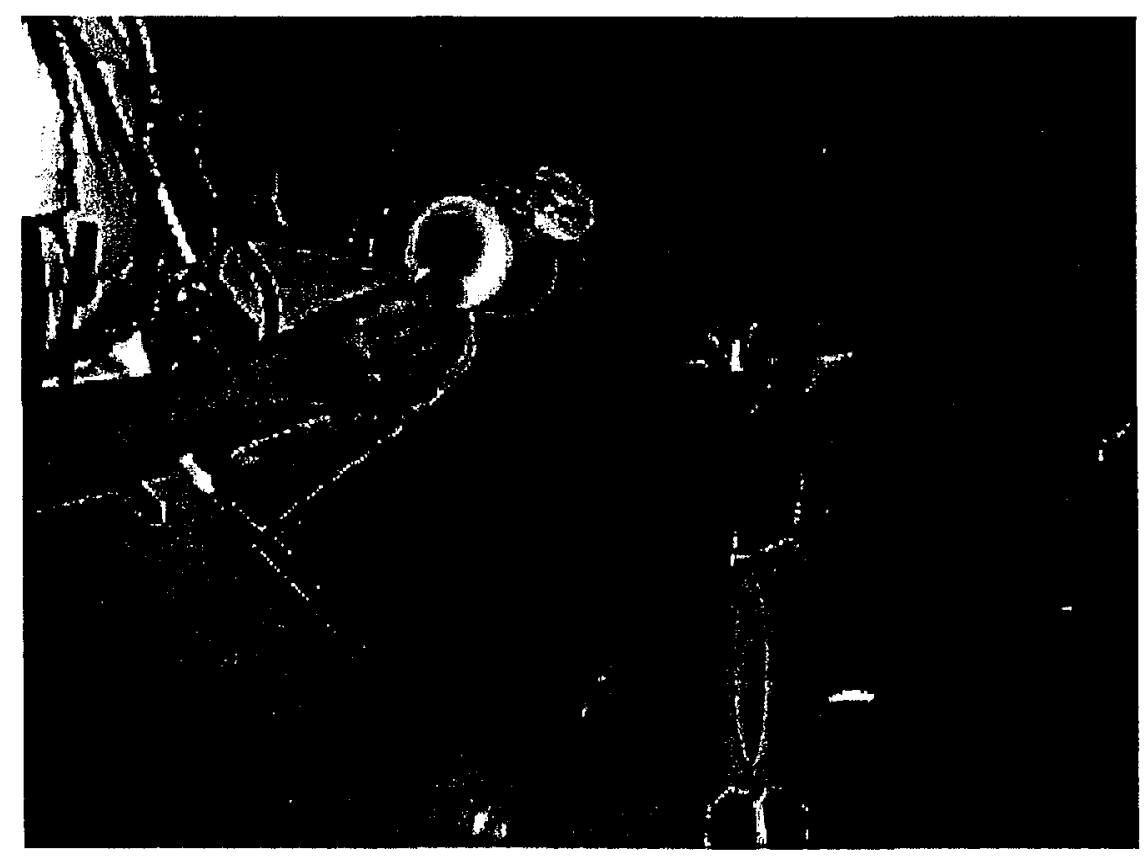

Fig. 6. The medium, inoculated with pseudomonas $(O D=0.240)$ and yellow microspherules $\left(1.15 \times 10^{9}\right.$ beads $/ \mathrm{ml}$ ), was applied to the left hand side of the seam of each pad (red oval). The red arrow points toward the Heated Drift end of the liner. 


\section{B. Heated Drift emplacement.}

The Heated Drift was inoculated with microbes in a single area along the left wall (facing the rear of the drift). The location was chosen such that its proximity to chemical analysis boreholes (boreholes \#52-56 and 69-73) would maximize the retrieval potential. In addition, our aim was to require minimal modification of the wall surface. For this reason the Heated Drift wall was surveyed for large fracture openings (Fig. 7) and unused rockbolt holes in the vicinity of the area between wing heaters \# 4 and 5 (emplaced into boreholes \#86 and 87) and between wing heaters \# 15 and 16 (emplaced into boreholes \# 97 and 98).

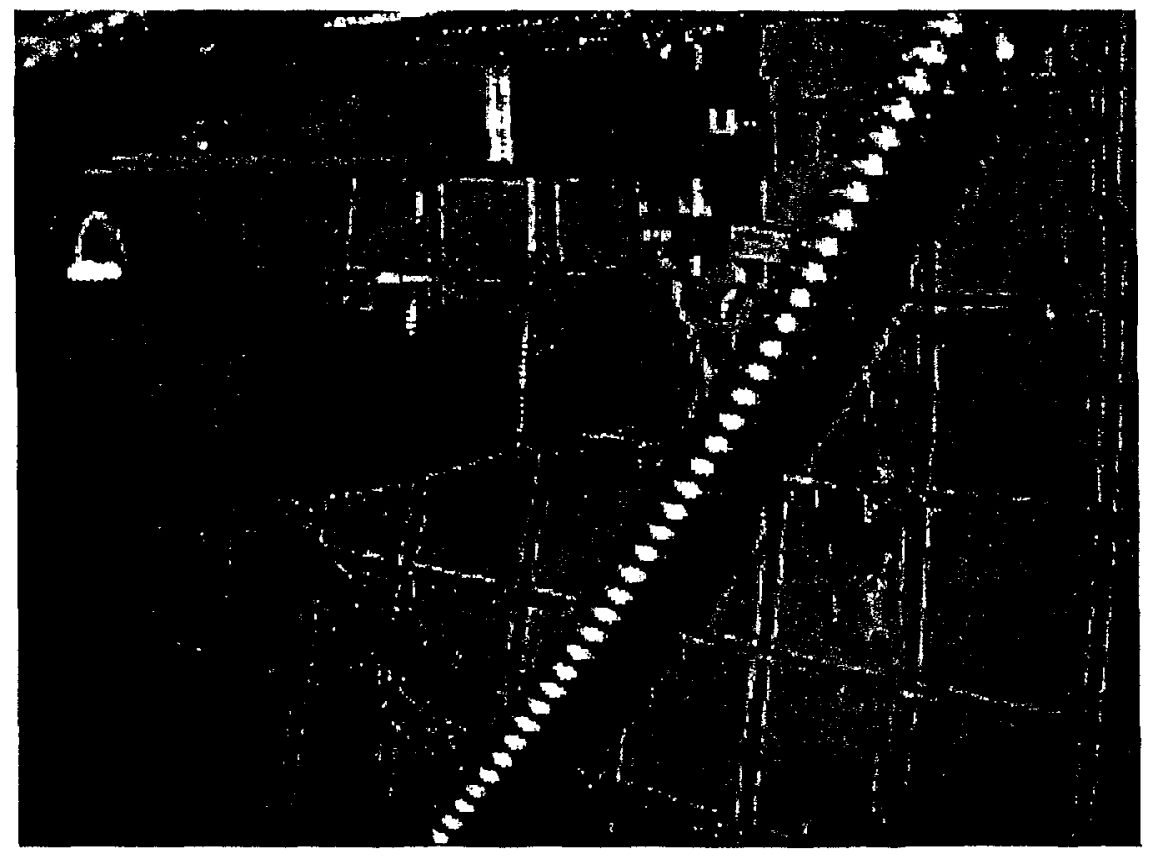

Fig. 7. Measurement of fracture apertures indicated that in the area selected for inoculation, unused rockbolt holes were a more suitable choice. The green paint is an artifact of construction.

Measurement of fracture apertures indicated that in the area selected for inoculation, unused rockbolt holes in the vicinity of wing heaters \# 4 and 5 were the most suitable choice. The location of the four rock bolt holes used for inoculation are sketched in Figure 8. Wing heater electrical circuitry boxes to the lower left of each wing heater borehole are used for reference to locate inoculation points (Fig. 9). Wire mesh and conduit cover much of the rock surface. 
conduit
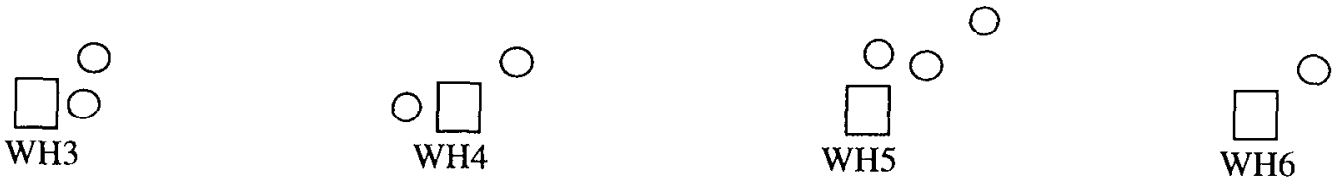

Fig. 8. Sketch (with vertical exaggeration) of location of unused rockbolt holes (red circles) used for Heated Drift wall inoculation with relation to wing heater (WH) boxes and boreholes (blue) and the conduit (black).

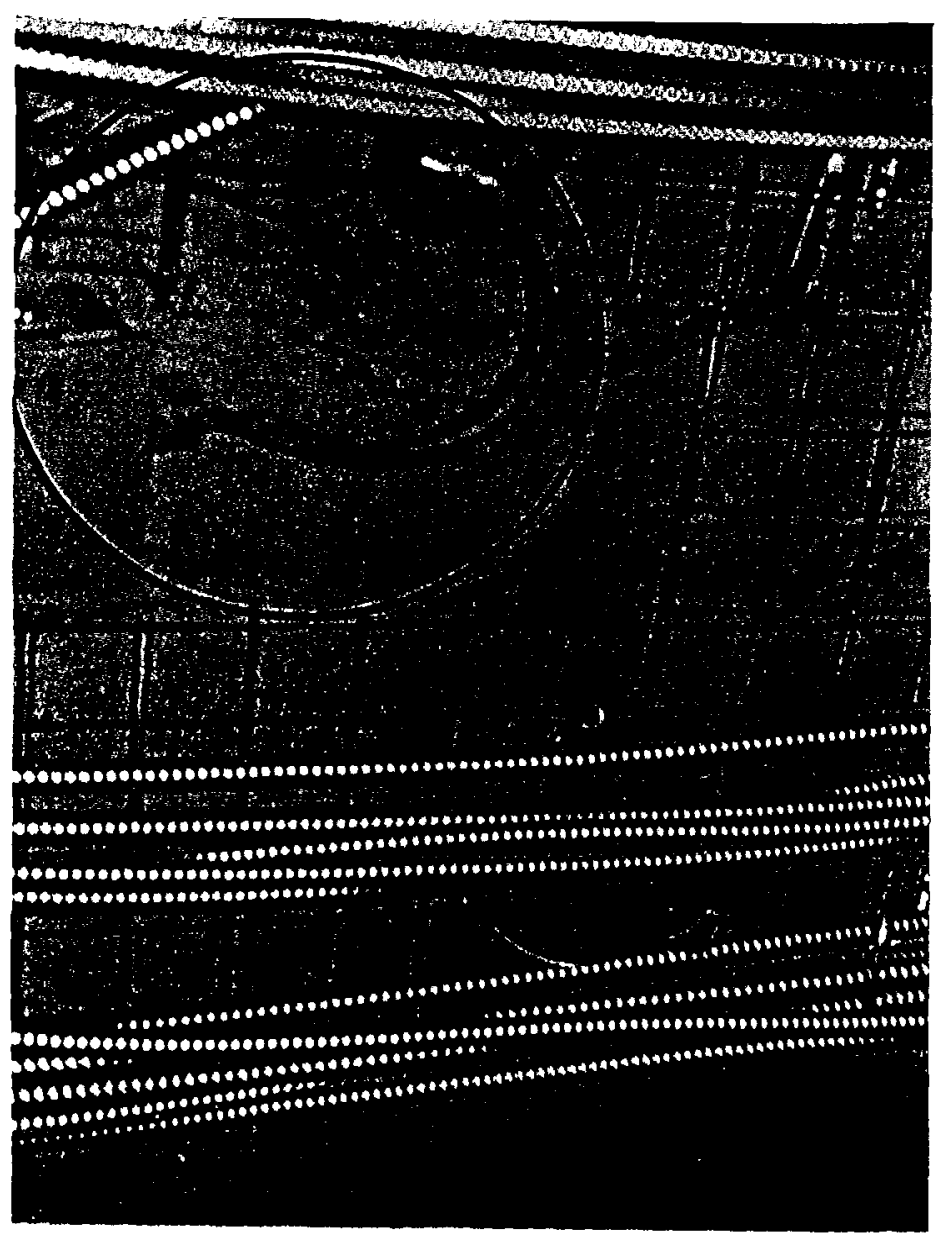

Fig. 9. Wing heater assembly near migration/survival installation 
site (blue circle). Note that wire mesh and conduit cover most of the rock surface.

The inoculum was formulated such that it could be distinguished from the inoculum installed in the borehole liners. Media inoculated with double drug resistant (rifampicin and streptomycin) bacillus subtillus and red microspheres and double drug resistant (rifampicin and streptomycin) arthrobacter oxidans and red microspheres were siphoned alternately into unused rockbolt holes (circled, Fig. 10). A total of $4000 \mathrm{ml}$ of labeled arthrobacter oxydans inoculated medium $(\mathrm{OD}(660 \mathrm{~nm})=0.435)$ and $4000 \mathrm{ml}$ of labeled Bacillus subtillis inoculated medium $(\mathrm{OD}(660 \mathrm{~nm})=0.470)$ was emplaced into the drift wall (Fig. 11). 800 $\mathrm{ml}$ of mixed medium was emplaced on the lining between two sections of invert located immediately below wing heater (WH) \#4.

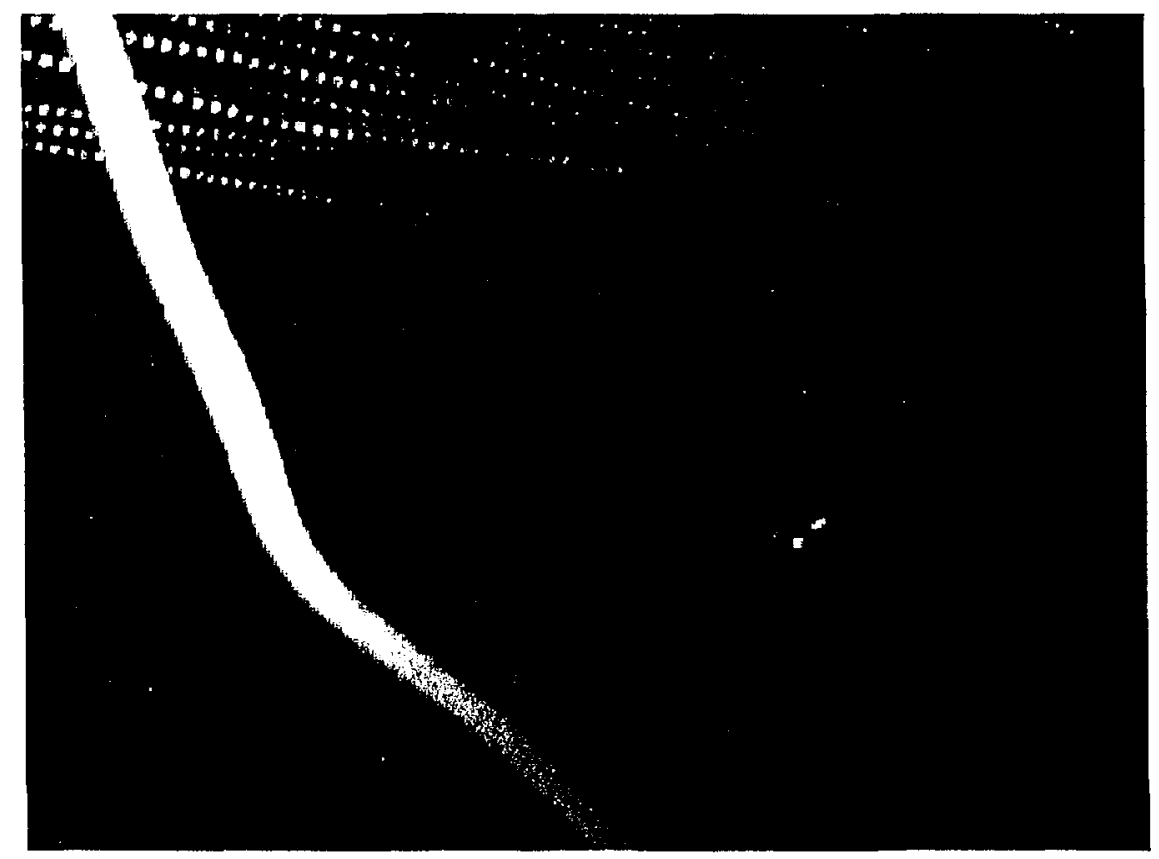

Fig. 10. Inoculated media were siphoned alternately into the rock from two carboys. Onc contained arthrobacter oxydans and the other bacillus subtillus.

\section{Survival/material-microbe-rock interaction test.}

The location of the introduced material/tuff/microbe interaction experiment was chosen at the intersection of the rock wall and the concrete liner (Fig. 12 and Fig. 3). The carbon steel/tuff/microbe test location was chosen in the rock wall roughly 16 inches above the invert level (Fig. 13), and roughly two feet from the edge of the concrete liner. Nine holes were drilled in tuff for this test, roughly 3 inches apart (Fig. 14). Drilled rock fragments were collected using sterile methods in order to reintroduce the material into the holes after 
the inoculum and samples have been inserted. After the depth of the hole was determined to be adequate (Fig. 15), the test materials were emplaced as shown in Figure 16. Microbes only were emplaced in holes 1-3. Microbes and carbon steel were emplaced in holes 4-6. The microbe inoculum cocktail of sulfolobus and thiobacillus bacteria was inserted using a sterile pipette (Fig. 17). Carbon steel only was emplaced in holes 7-9. All holes were backfilled with rock powder that was collected by steril methods (Fig. 18).

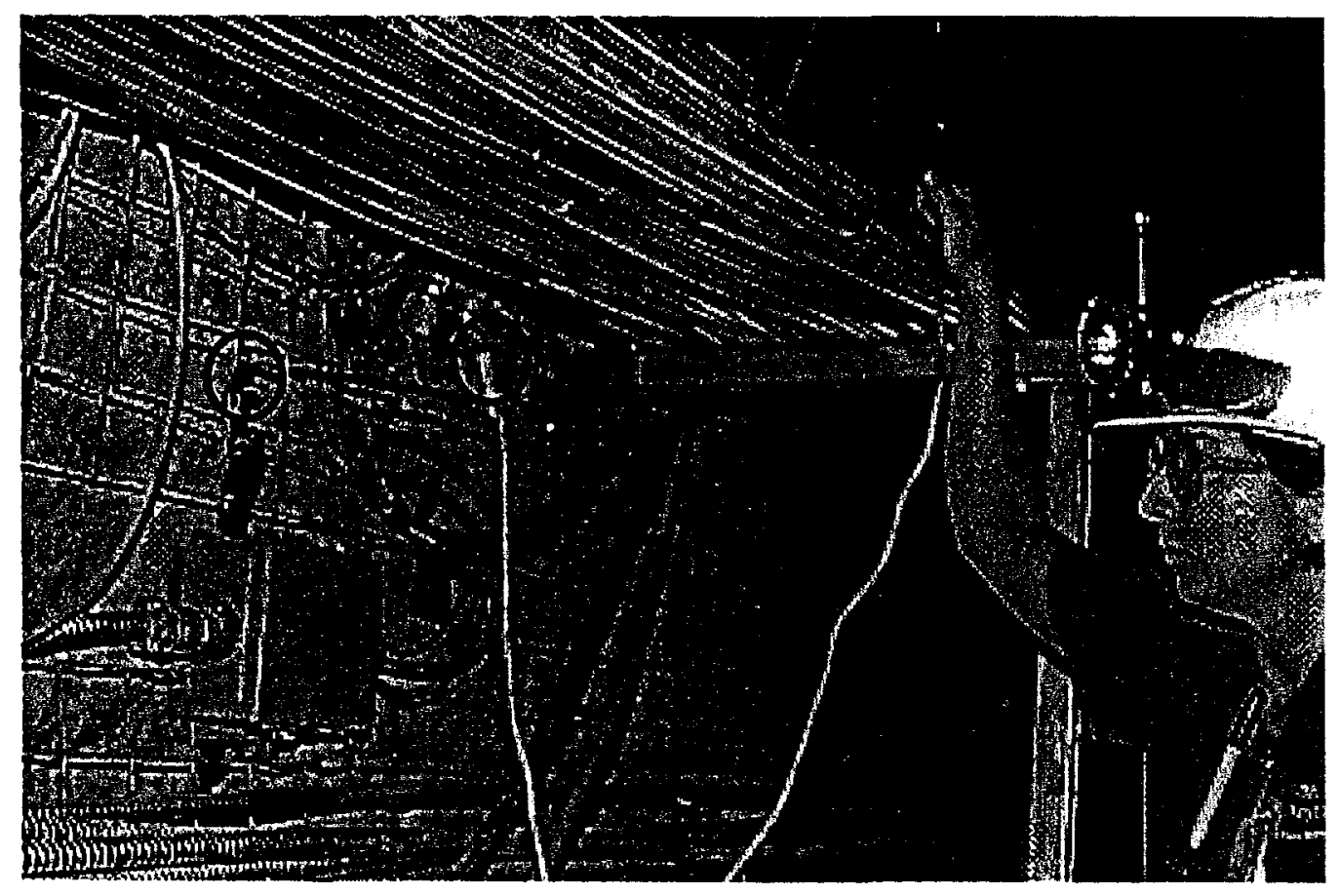

Fig. 11. A total of $8000 \mathrm{ml}$ of inoculated medium was emplaced into unused rockbolt holes (circled) in the drift wall. Conduit is located above rockbolt holes.

A sliced concrete core and metal alloy coupons were placed directly in front of the inoculated tuff (Fig. 19). The core was collected from ESF invert (\#SPC00507875) and prepared at LLNL. The sliced concrete core contains samples of two alloys (516-70 and 588) between the top four slices designated by the letters A-E in Figure 19. The sample coupons were laid in each slice (A (516-70\#48 and 588\#48), B(516-70\#47 and 588\#47), $\mathrm{C}(516-70 \# 46$ and 588\#46)) such that there was no contact between coupons. The bottom slices contain a control (uninoculated) (D) and a layer of sulfolobus and thiobacillus (E). The alloy coupons are positioned in two rows, where a row of I-686 alloy is closest to the wall and the row of A588 alloy is adjacent. The sample numbers (25-30) are designated in Figure 19. 


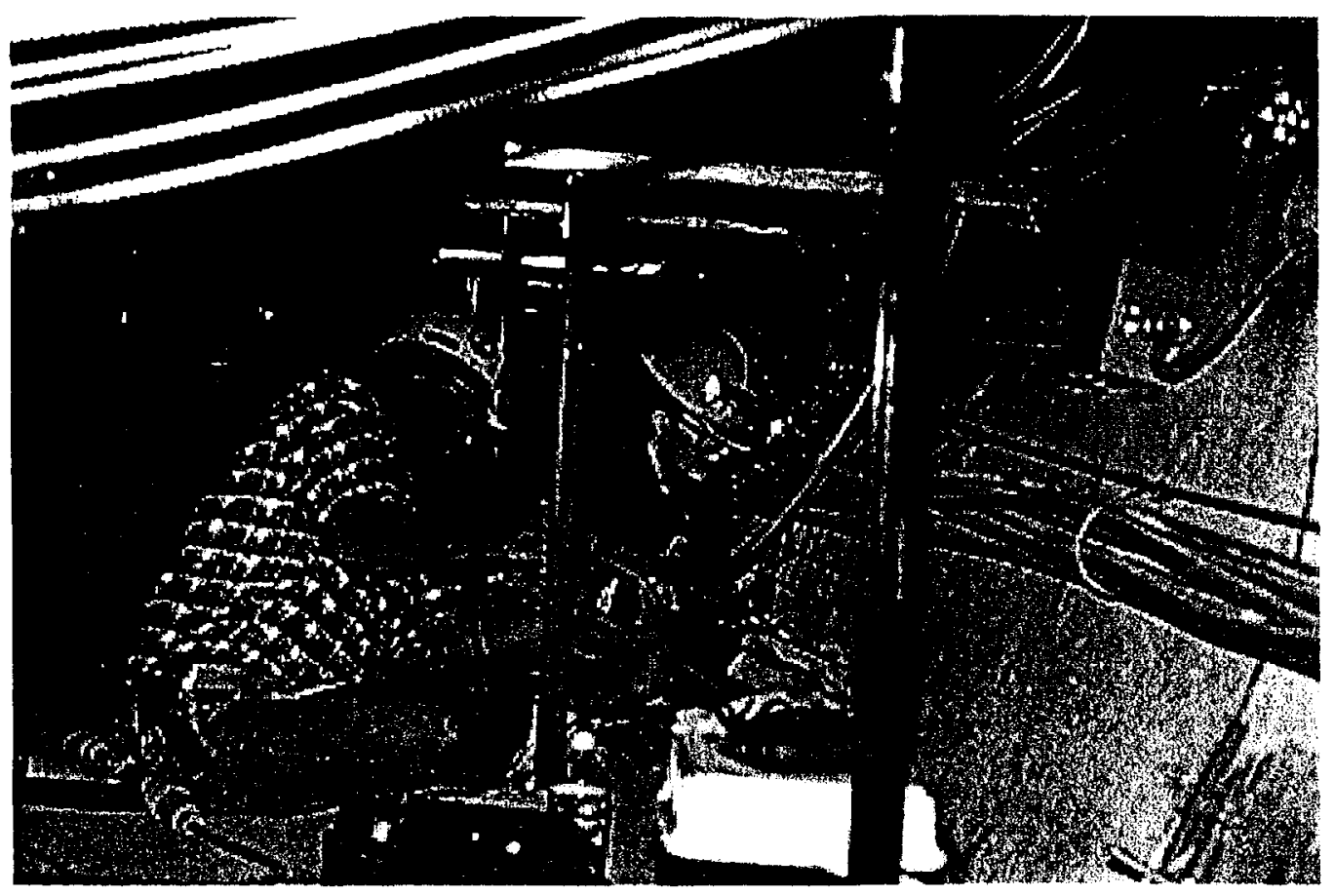

Fig. 12. Location of microbe/tuff/material interaction experiment. For a location reference see circled yellow hard-hat in Fig. 3.

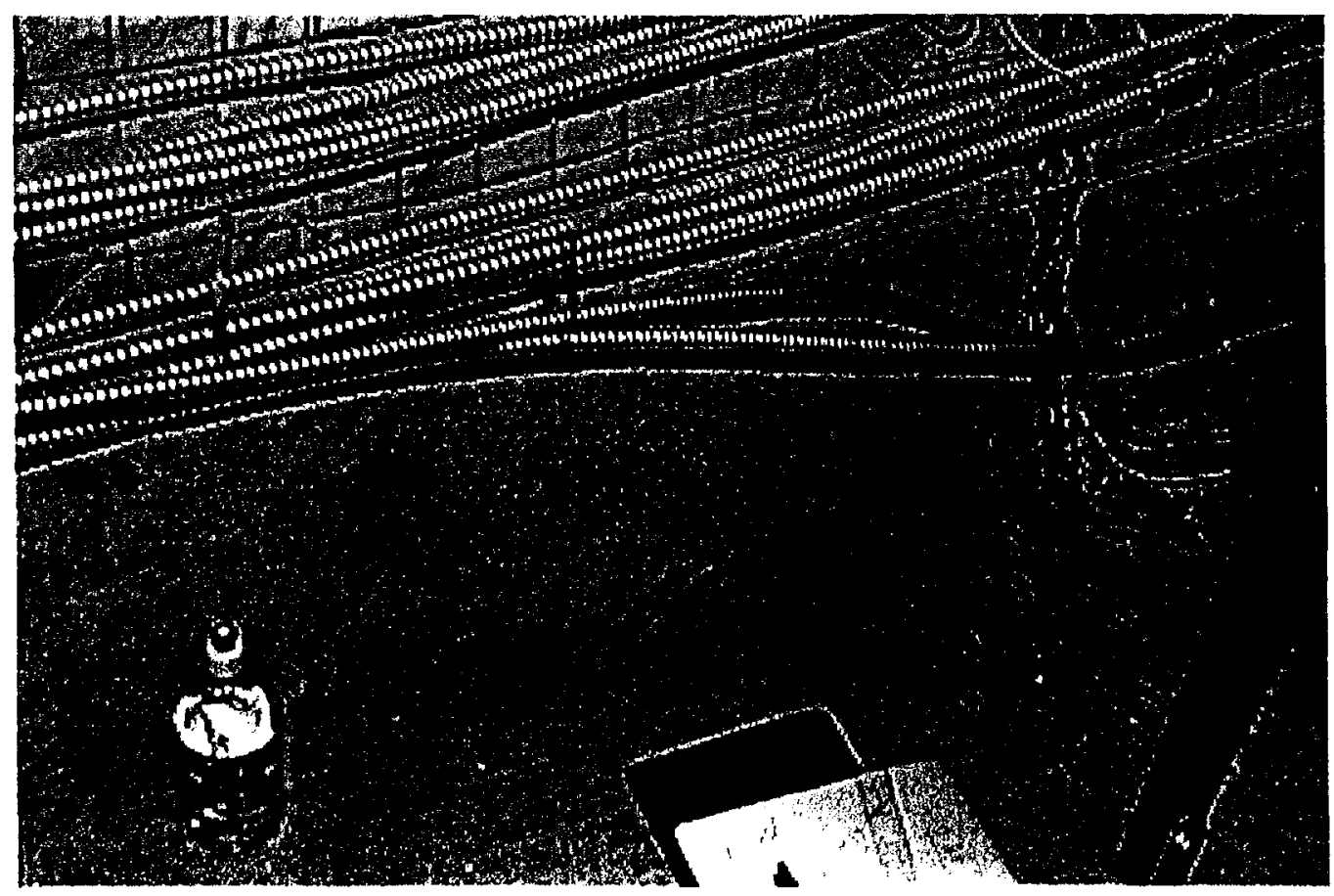

Fig. 13. Location of holes for carbon steel/tuff/microbe experiment. The drips on the right side of the photograph are dried epoxy resin from construction. 


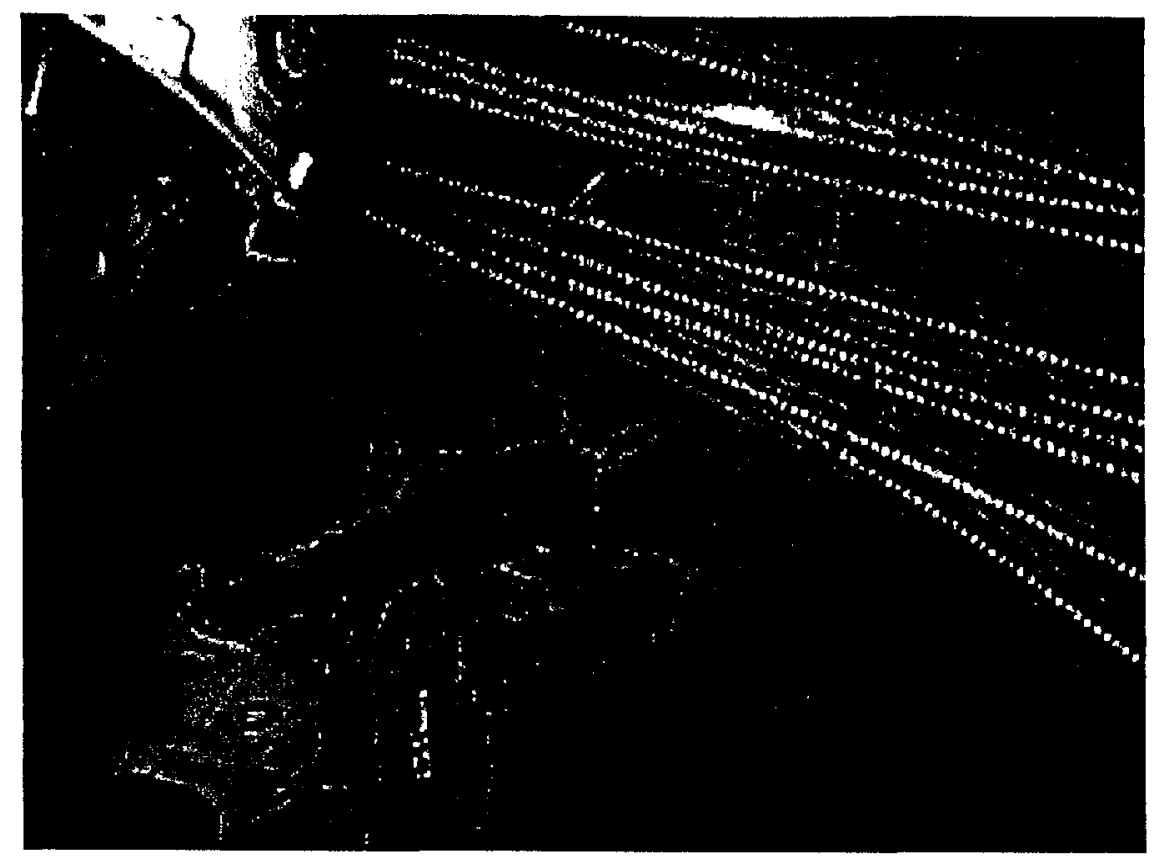

Fig. 14. Nine holes were drilled in tuff for this test. Rock fragments were collected using sterile methods to reintroduce into the holes after the inoculum and samples were inserted.

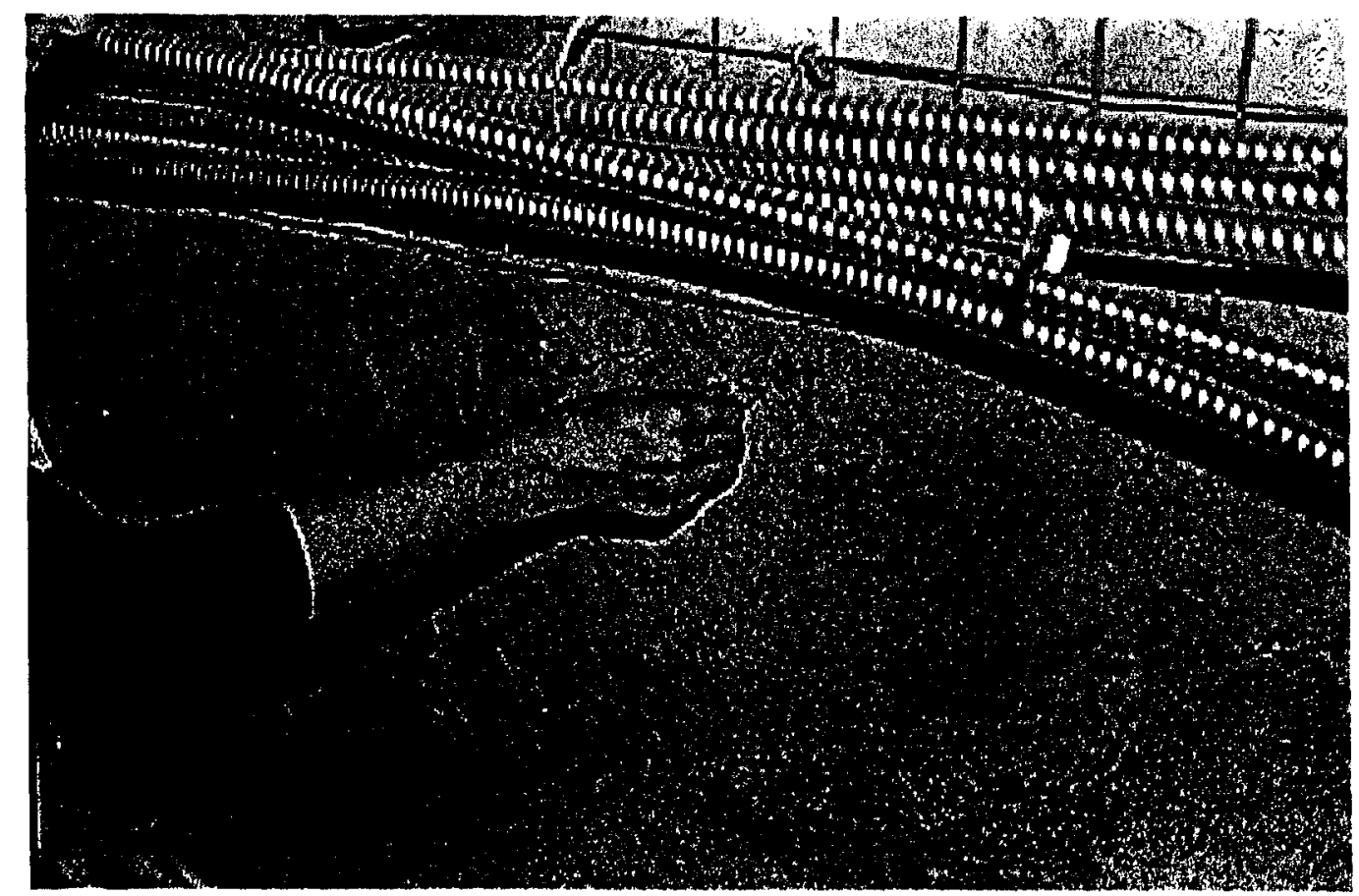

Fig. 15. Measurement of the depth of a drilled hole. 


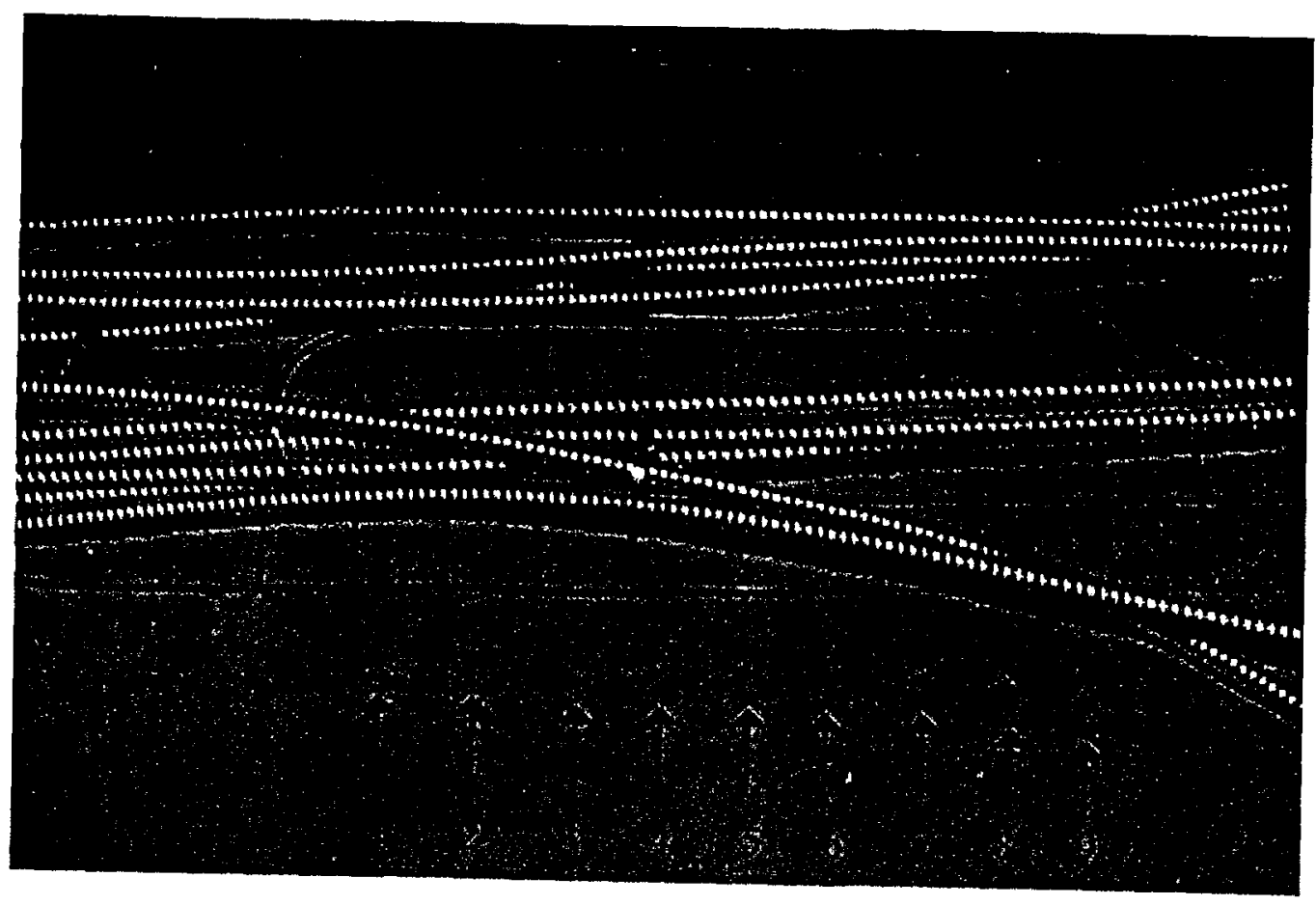

Fig. 16. Tuff emplacement holes completed. Holes 1-3 contain microbes only, 4-6 contain microbes and metal coupons, 7-9 contain metal coupons only.

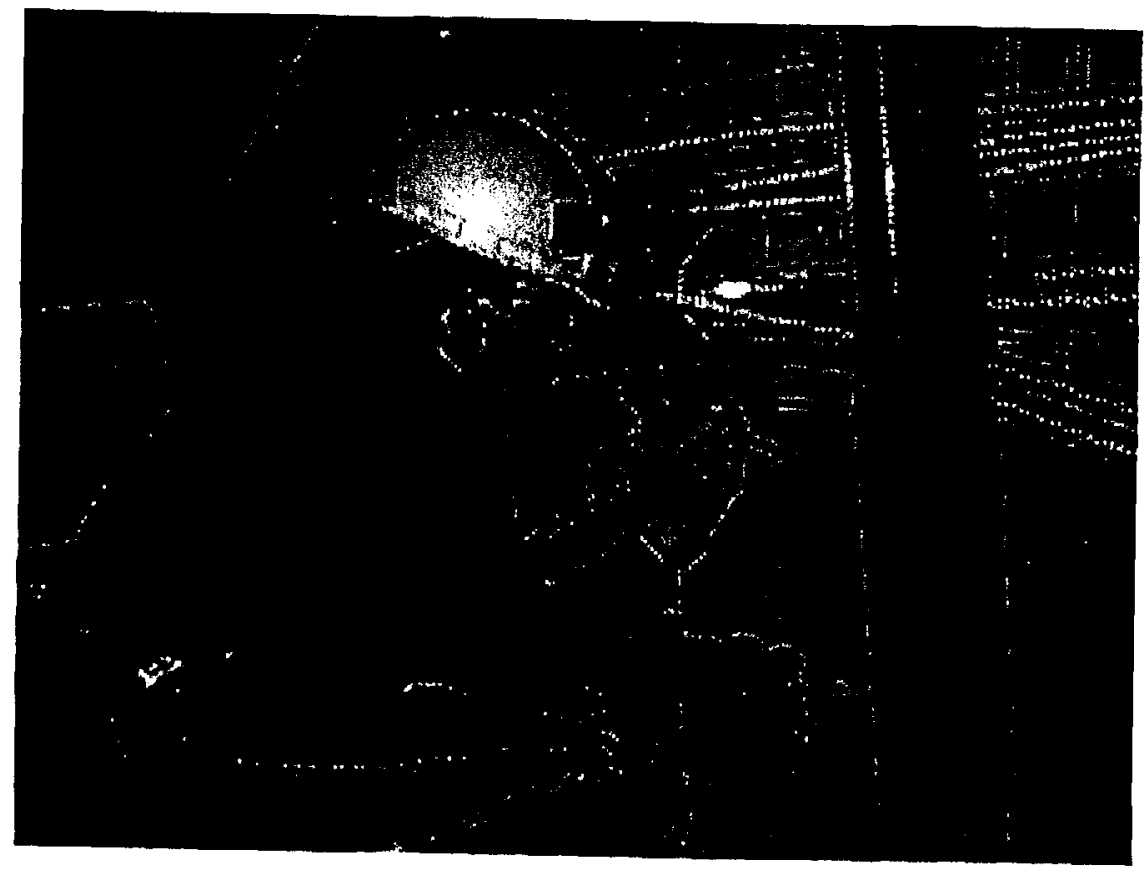

Fig. 17. Inoculum cocktail of sulfolobus and thiobacillus bacteria was inserted with a sterile pipette into three holes. 


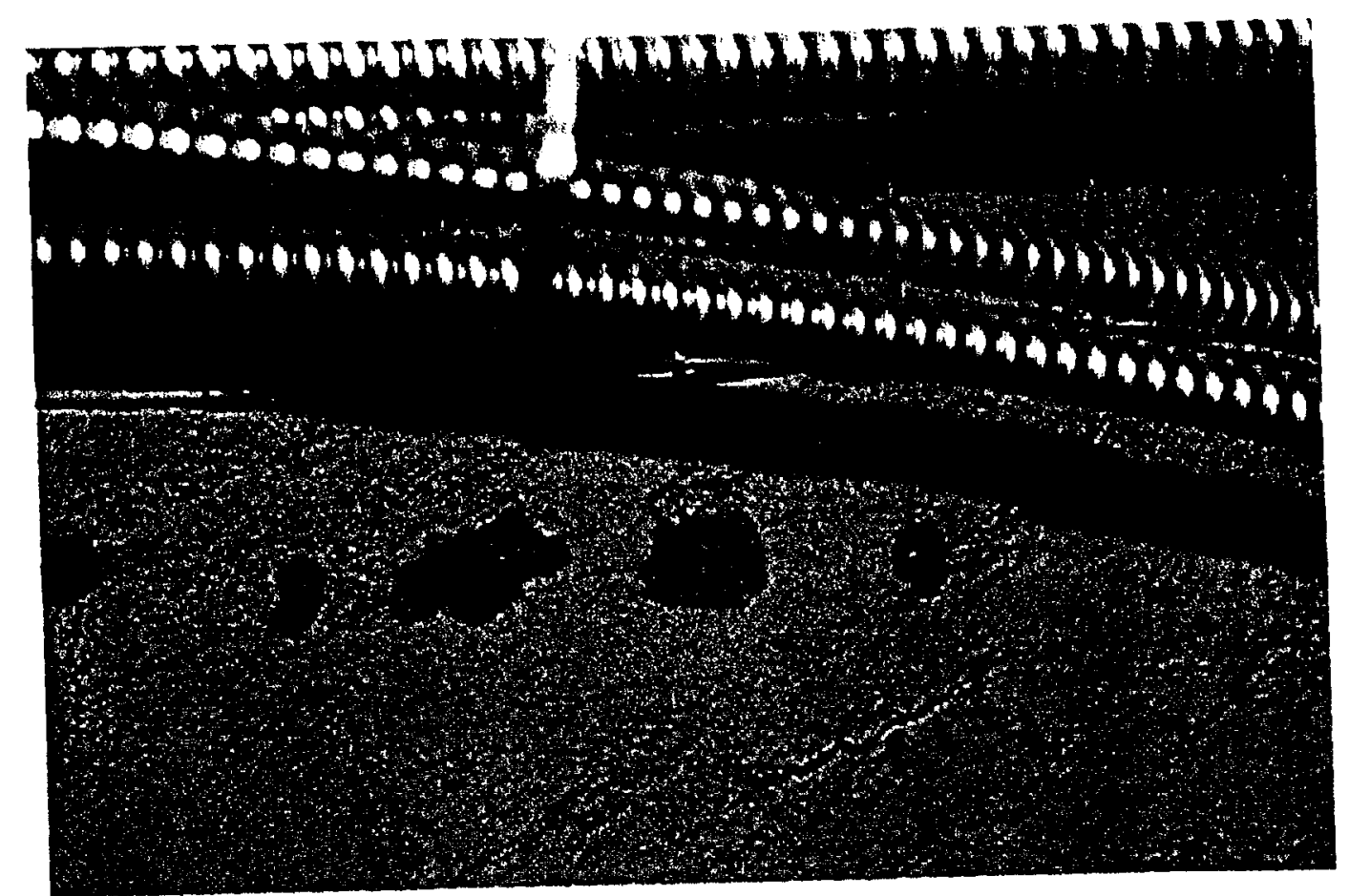

Fig. 18. Inoculated tuff. The two left hand holes contain microbes only. The three central holes contain carbon steel coupons and microbes. Three holes to the right (not visible in this photo) contain carbon steel only.

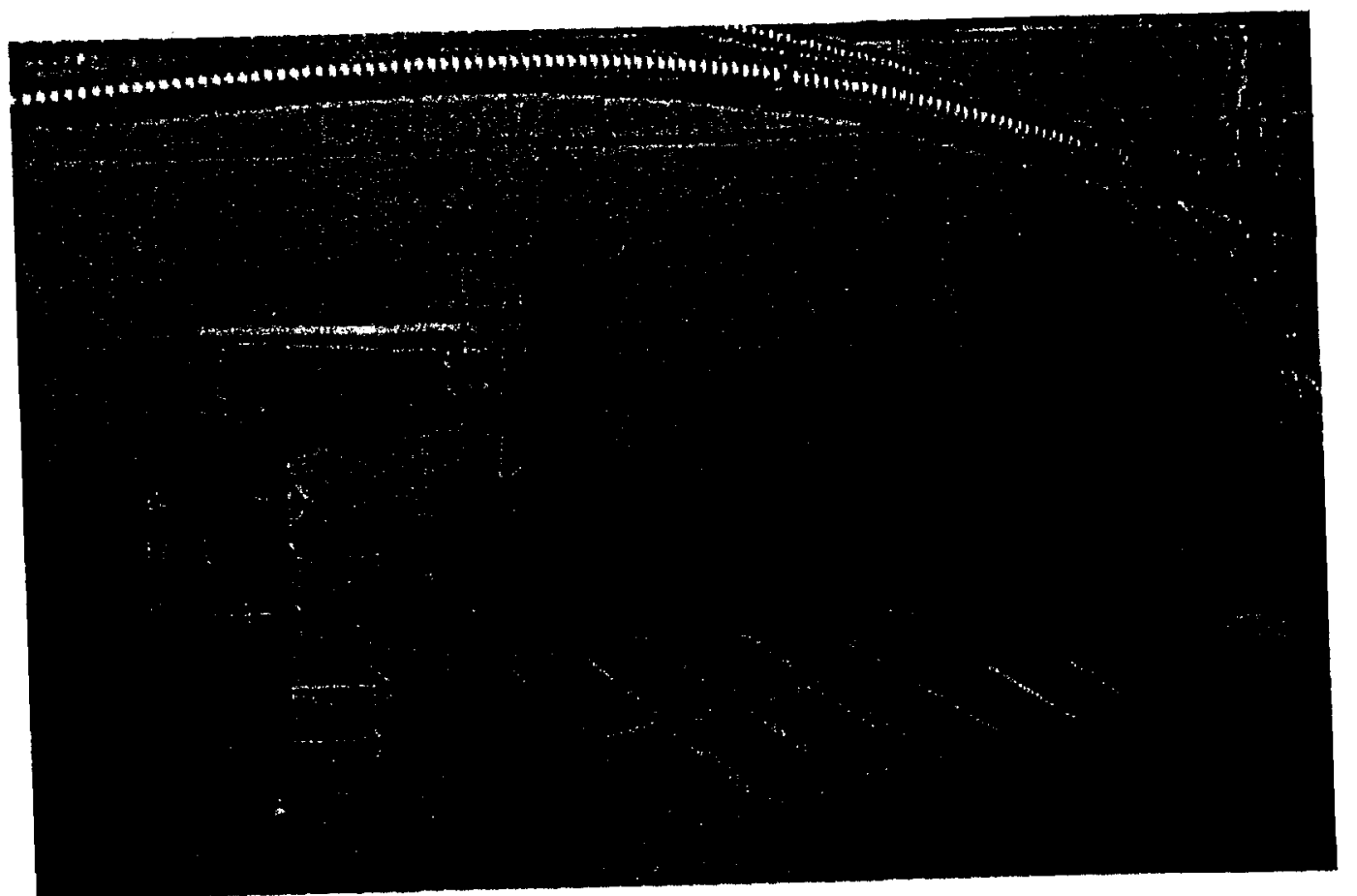

Fig. 19. Location of drilled and inoculated tuff holes with respect to metal alloy and concrete core samples. The sliced concrete core and alloy samples are explained in the text. 
The emplacement of material for the carbon steel/microbe/concrete experiment was identical to the tuff emplacement (Figs. 20-23) except in this case the holes were hackfilled with concrete powder that was collected by sterile methods.

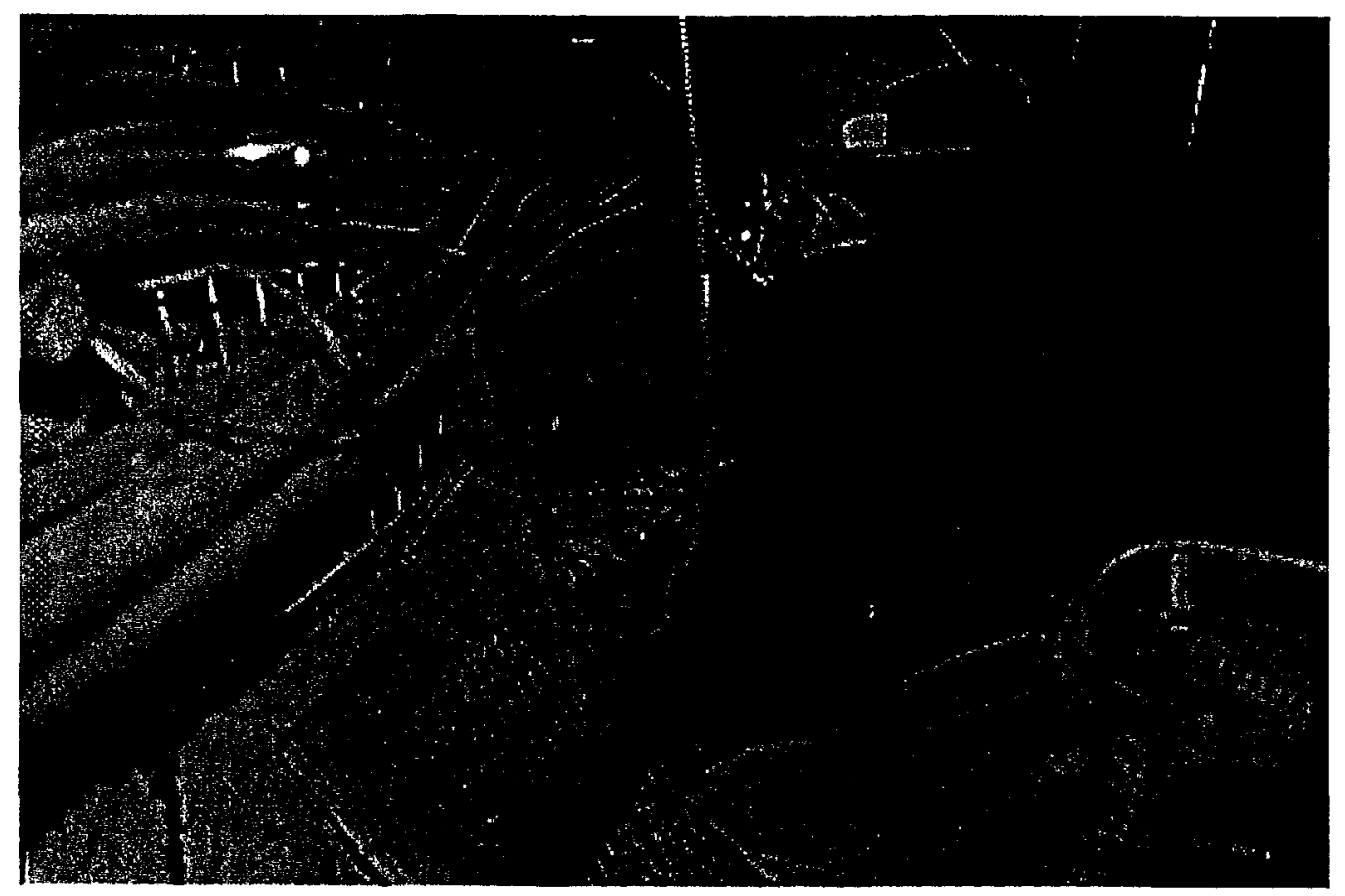

Fig. 20. Holes drilled in concrete liner adjacent to tuff installation.

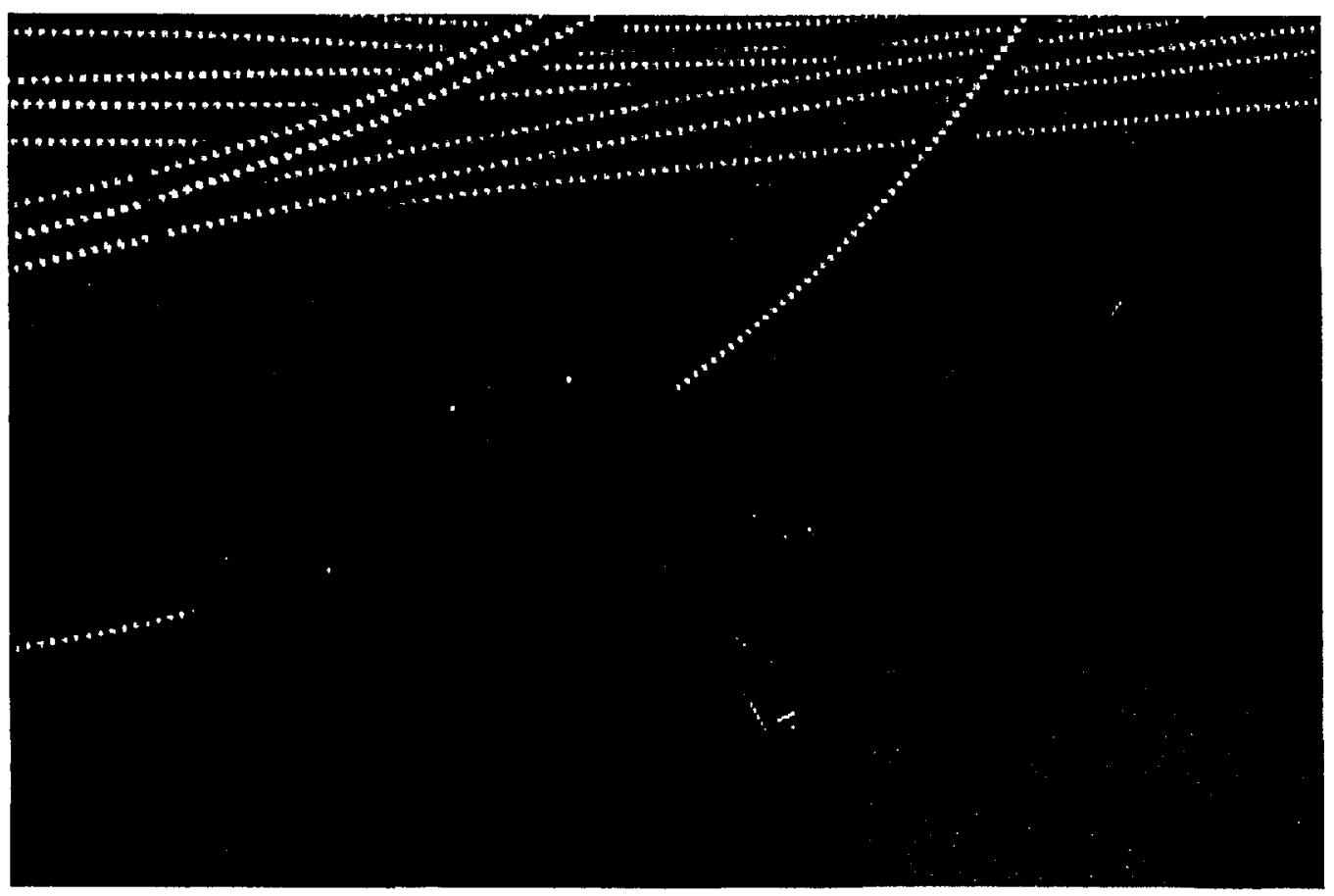

Fig. 21. Collection of drilled concrete fragments. 


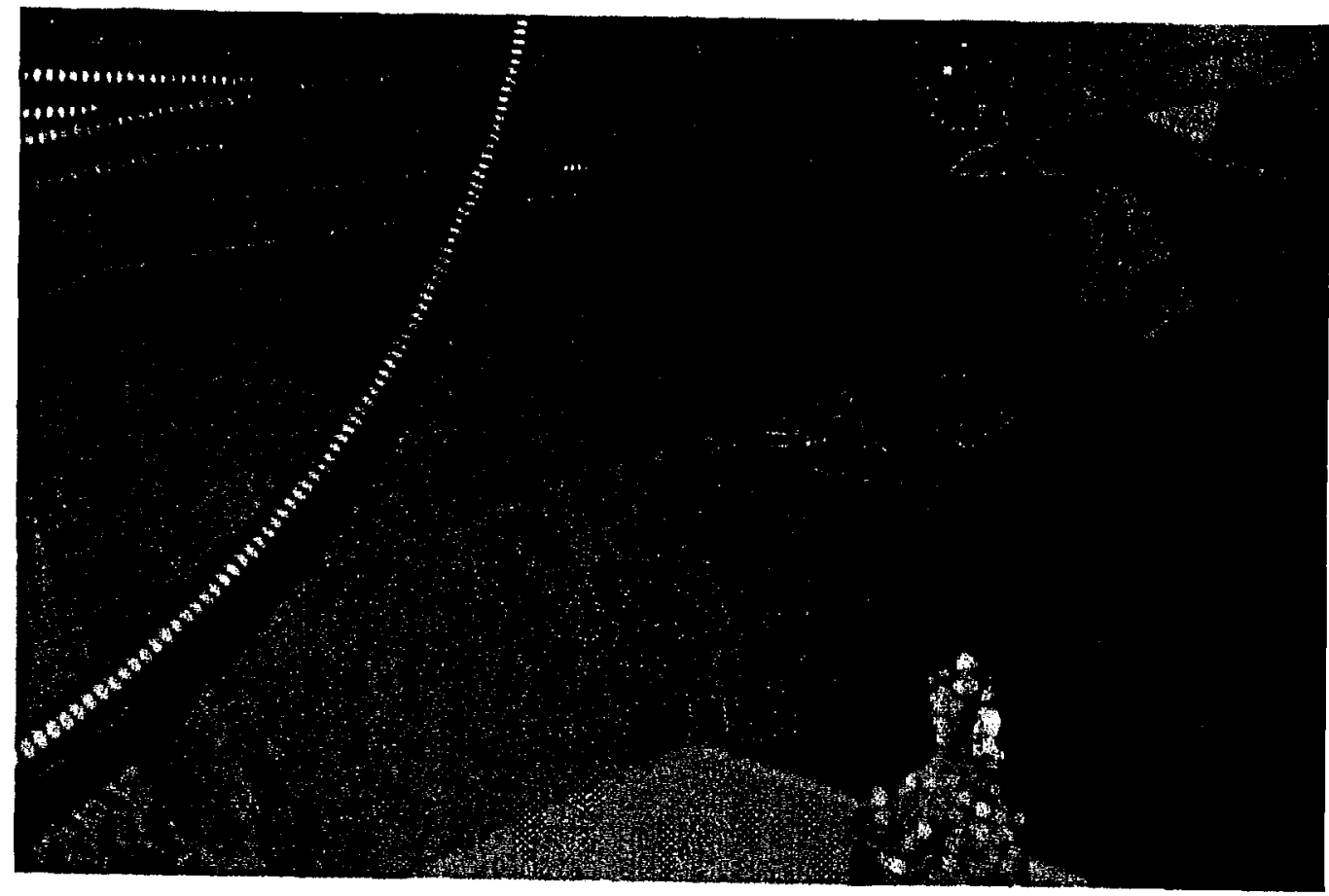

Fig. 22. Emplacement of a carbon steel coupon.

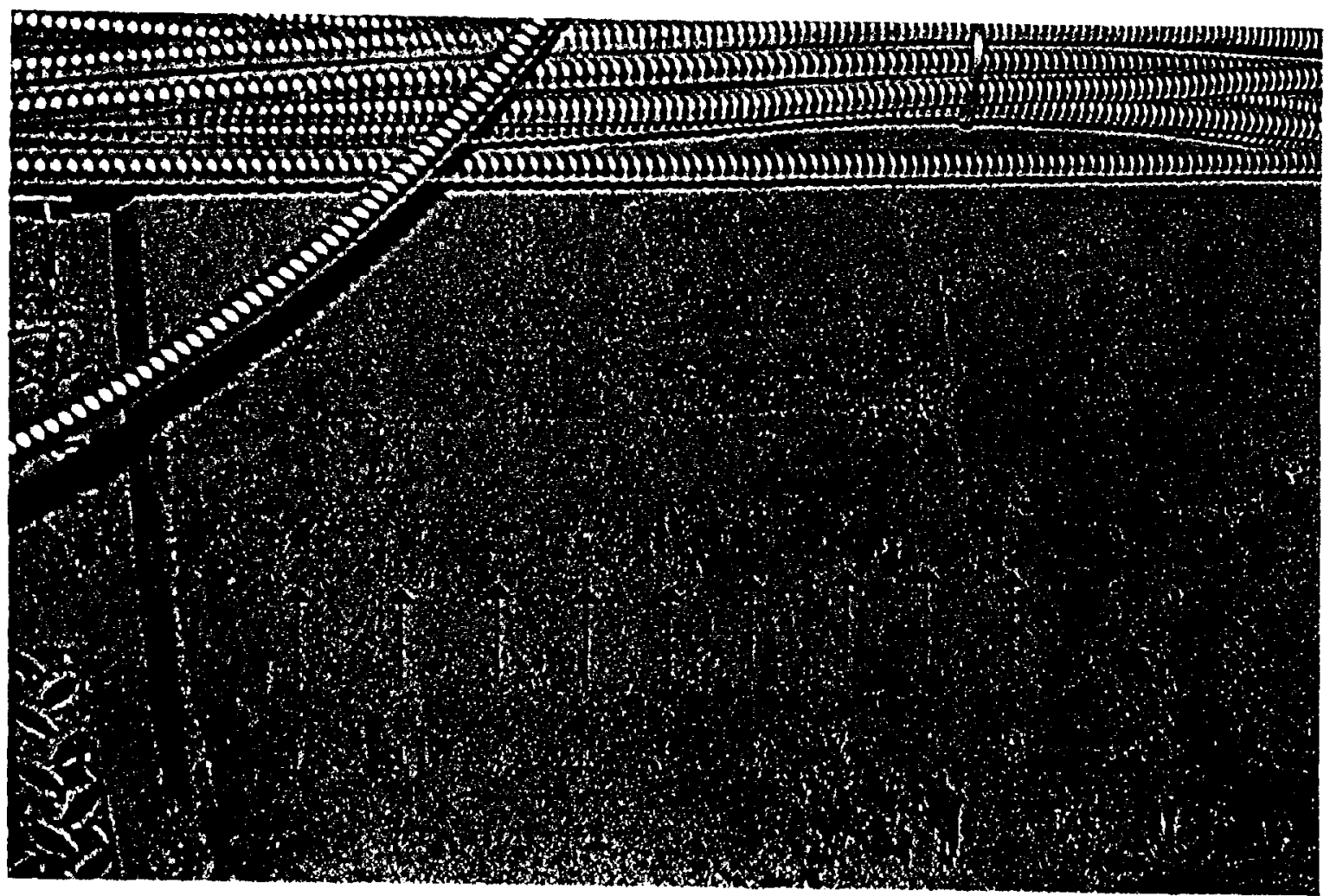

Fig. 23. Concrete emplacement holes completed. Similar to the tuff emplacement, holes 1-3 contain microbes only, 4-6 contain microbes and metal coupons, and 7-9 contain metal coupons only. 


\section{Sterile collection and freezing of pre-test rock sample.}

The final task described in this report is the sterile collection and freezing of a pre-test rock sample. Our intent is to archive this sample in order to refer to it for comparison to a post- test sample. It is assumed that a post-test sample can be taken from an adjacent location soon after the bulkhead is opened, so as to prevent the possibility of contamination. A split sample (\#SPC00525097) was collected from the back wall of the heater drift to the right of the heaters (Fig. 24). The samples was transported on ice to its archive destination. Half of the sample is archived with P. Amy at UNLV and half is archived with C.-I. Chen at LLNL.

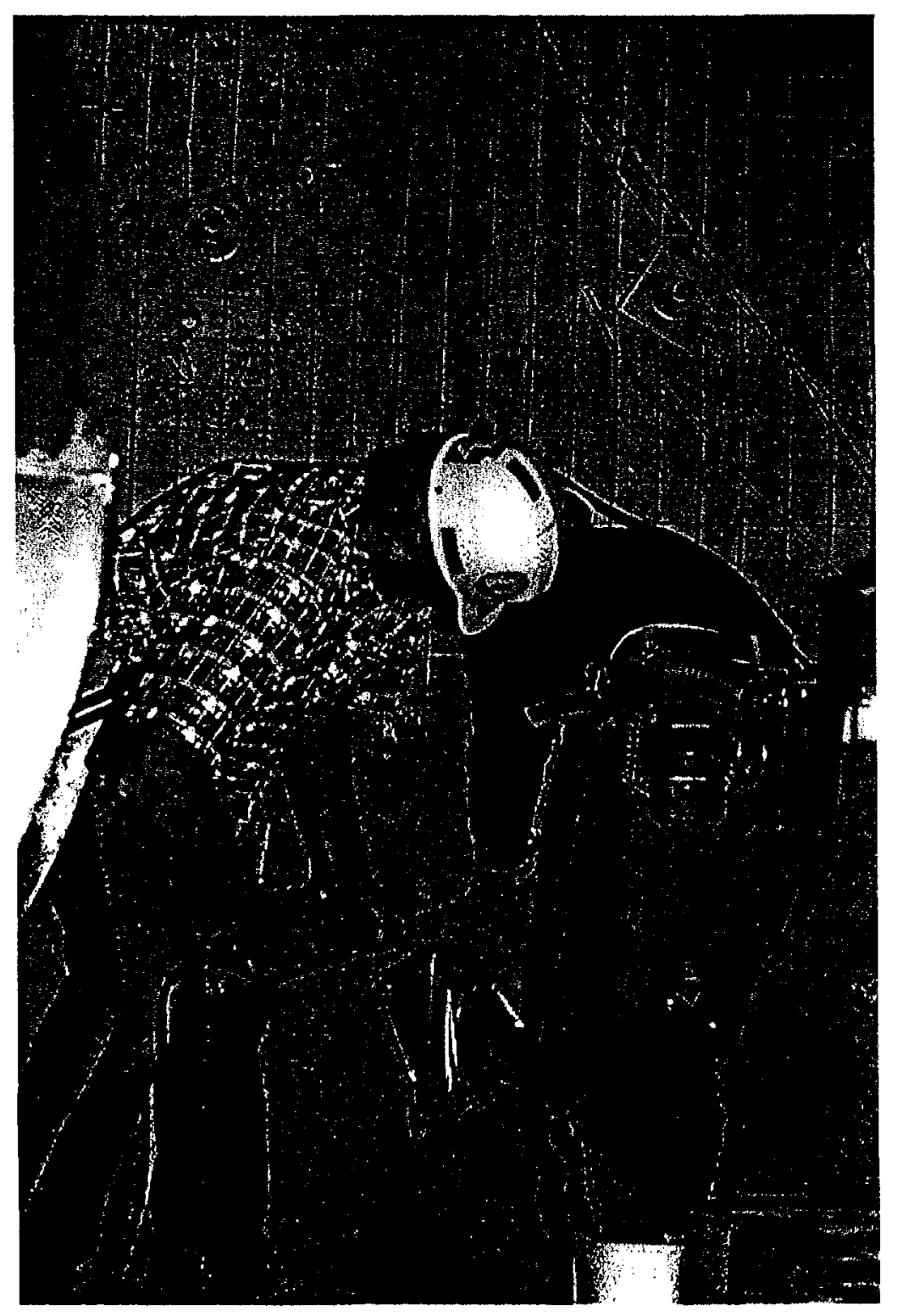

Fig. 24. Sterile collection of pre-test tuff sample from the end of the heater drift. 
This sample has been archived for comparison to a post-test sample.

\section{Acknowledgments}

Special thanks to Carl Keller for collaboration on the microbe emplacement on the Seamist ${ }^{\mathrm{TM}}$ liners, and to Troy Williams Doug Weaver, and Alan Mitchell for coordination of the work in the ESF. Further technical information is documented in SN \# 240, 266, $273,281,284,311,341$ and 326.

\section{References}

Horn, J. M., and A. Meike (1995) "Microbial Activity at Yucca Mountain", UCRL-ID122256.

Weaver, D. J. (1996) "Schematic Illustration of Heated Drift Borehole Arrangement" Electronic File Name: HEATDRF6.DWG Rev.A2 Autocad R12. Drawing Dated: 10/3/96. 


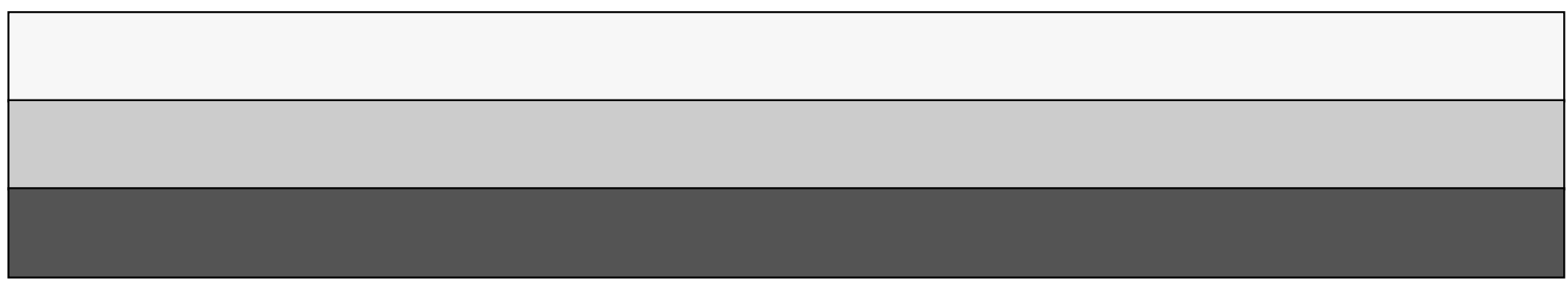

